\title{
Risk factors for the acquisition of extended-spectrum beta-lactamase- producing Enterobacteriaceae in hospitalized children
}

\author{
Luciana Robino ${ }^{1,2}$, Hector Telechea ${ }^{2,3}$, Noelia Speranza ${ }^{3}$, Virginia García-Fulgueiras ${ }^{1}$, Nicolás Cordeiro ${ }^{1}$, \\ Inés Bado ${ }^{1}$, María Inés Mota ${ }^{1,4}$, Gustavo Giachetto ${ }^{2}$, Gabriela Algorta ${ }^{1,4}$, Rafael Vignoli ${ }^{1}$ \\ ${ }^{1}$ Departamento de Bacteriología y Virología, Instituto de Higiene, Facultad de Medicina, Universidad de la \\ República, Montevideo, Uruguay \\ ${ }^{2}$ Departamento de Pediatría, Centro Hospitalario Pereira Rossell, Facultad de Medicina, Universidad de la \\ República, Montevideo, Uruguay \\ ${ }^{3}$ Departamento de Farmacología y Terapéutica. Hospital de Clínicas “Dr. Manuel Quintela”, Facultad de Medicina, \\ Universidad de la República, Montevideo, Uruguay \\ ${ }^{4}$ Laboratorio Central del Hospital Pereira Rossell, Ministerio de Salud Pública, Montevideo, Uruguay
}

Key words: ESBL; risk factor; Enterobacteriaceae

J Infect Dev Ctries 2013; 7(4):361-364. doi:10.3855/jidc.3014

(Received 14 September 2012 - Accepted 30 October 2012)

Copyright (C) 2013 Robino et al. This is an open-access article distributed under the Creative Commons Attribution License, which permits unrestricted use, distribution, and reproduction in any medium, provided the original work is properly cited.

\section{Background}

Infections by extended-spectrum Beta-lactamases (ESBL)-producing Enterobacteriaceae (EPE) are an increasing problem in pediatrics and are usually associated with higher hospital costs, failure of the empirical antibiotic treatment, and higher mortality rates [1-4].

EPE usually include resistance to aminoglycosides or quinolones, mediated by genes such as $a a c\left(6^{\prime}\right) I b-c r$ and $q n r$ alleles [5-7].

Data concerning prevalence and risk factors (RF) for EPE infections in the general pediatric population are scarce, mostly associated with bacteremia, and only a few include molecular identification of ESBLs $[2,8]$.

\section{The study}

We performed a case-control study (1:2 ratio) in the Hospital Pediátrico Centro Hospitalario Pereira Rossell (HP-CHPR), Montevideo, Uruguay, enrolling patients admitted into the pediatrics wards (PW) and the intensive care unit (ICU) between 1 May 2009 and 30 April 2010.

Patients with clinical isolates of EPE and non-EPE were defined as cases and controls, respectively. Both groups were paired according to the origin of the sample to ensure similar epidemiological conditions. Due to the proportion of EPE infections within the
ICU, we extended the collection period to gather the required number of controls.

Only one isolate per patient was taken into consideration for this study.

Identification and antibiotic susceptibility testing were performed using the Vitek2 Compact system (bioMérieux, Marcy l'Etoile, France) and interpreted following CLSI recommendations [9].

ESBL genes ( $b l a_{\mathrm{CTX}-\mathrm{M}}, b l a_{\mathrm{TEM}}, b l a_{\mathrm{PER}-2}$ and $\left.b l a_{\mathrm{SHV}}\right)$ and $q n r A, q n r B$, qnrS and $a a c\left(6^{\prime}\right) I b / a a c\left(6^{\prime}\right) I b$-cr were identified by PCR and sequencing [5].

Patient data was obtained from clinical records (age; gender; ward; total length of stay; length of stay since acquisition of infection; presence of nosocomial infection [10]; hospitalization in PW or ICU in the previous six months; use of third-generation cephalosporins (TGC) during the last month; presence of underlying chronic illnesses). We also registered the empirical antibiotic therapy (EAT), adjusted therapy according to the susceptibility report, and noted the success of the empirical and/or adjusted therapy (i.e., apyrexia or clinical improvement after 72 hours of antibiotic therapy, and/or negative bacterial cultures).

Numeric variables were compared using the T-test; $\chi^{2}$ or Fisher's exact test were used for variables divided into categories.

A multivariate analysis was performed using logistic regression including variables with a $\mathrm{P}$ value 
less than 0.2 on the univariate analysis. A two-tailed P value less than 0.05 was considered statistically significant. Statistical analyses were performed using SPSS 17.0 software (IBM SPSS Inc., Chicago, IL, USA).

This study was approved by the Direction Board of the HP-CHPR.

A total of 104 Enterobacteriaceae strains were isolated from patients admitted into the PW and the ICU. Fifteen strains were identified as EPE, 6 out of $82(7 \%)$ in the PW and 9 out of $22(40 \%)$ in the ICU.

Distribution of strains from 15 cases and 30 controls is shown in Table 1.

EPE acquisition was associated with underlying chronic illnesses (11/6 EPE/non-EPE, OR: 11; CI95\%: 2.57-47.01); admission to the ICU within the last six months (12/4 EPE/non-EPE, OR: 75; CI95\%: 7.54745.72); use of third generation cephalosporins during the previous month (9/2 EPE/non-EPE, OR: 20.25; CI95\%: 3.45-118.79) and nosocomial infections by Enterobacteriaceae (13/16 EPE/nonEPE, OR: 5.68; CI95\%: 1.09-29.69). Two of 15 cases of EPE (children younger than 30 days old) did not present any of the aforementioned risk factors.

The multivariate regression analysis indicated that only hospitalization in the ICU within the last six months was associated with EPE infections (OR: 8.39; IC 95\%: 1.33-53.11).

The mean of hospitalization for detection of Enterobacteriaceae was 11 days for controls versus 23 days for cases $(\mathrm{P}=0.007)$.

The number of different antibiotic therapies used was significantly higher for cases than for controls ( $\mathrm{P}$ $<0.0001)$. As shown in Table 2, meropenem, ciprofloxacin and amikacin were used mainly in the case group (OR: 10.3; CI95\%: 2.1-49.2; OR: 9.33; CI95\%: 1.6-54.7; OR: 7; IC 1.17-42, respectively).

In 11/15 patients with EPE infections, the EAT did not cover the infecting microorganism. Clinical failure was observed in six cases: five with an incorrect EAT

Table 1. General characteristics of the study patients and strains

\begin{tabular}{|c|c|c|c|}
\hline Variable & $\operatorname{EPE}(n=15)$ & $\begin{array}{l}\begin{array}{l}\text { Non EPE } \\
(\mathrm{n}=30)\end{array} \\
\end{array}$ & P-value \\
\hline Mean age (months) & 25 & 30 & $-{ }^{a}$ \\
\hline \multicolumn{4}{|l|}{ Gender } \\
\hline Female & 6 & 14 & - \\
\hline \multicolumn{4}{|l|}{ Samples } \\
\hline - Urine & 9 & 8 & 0.05 \\
\hline - $\quad$ Blood & 4 & 11 & - \\
\hline - $\quad$ Skin & 0 & 8 & 0.04 \\
\hline - $\quad$ Respiratory secretions & 0 & 3 & - \\
\hline - $\quad$ Synovial fluid & 1 & 0 & - \\
\hline - $\quad$ Bloodstream catheter & 1 & 0 & - \\
\hline \multicolumn{4}{|l|}{ Strains } \\
\hline - $\quad$ Escherichia coli & 3 & 13 & - \\
\hline - $\quad$ Klebsiella pneumoniae & 8 & 6 & 0.04 \\
\hline - Enterobacter cloacae & 2 & 4 & - \\
\hline - $\quad$ Serratia marcescens & 2 & 1 & - \\
\hline - $\quad$ Shigella spp & 0 & 3 & - \\
\hline - $\quad$ Salmonella spp & 0 & 2 & - \\
\hline - $\quad$ Morganella morganii & 0 & 1 & - \\
\hline \multicolumn{4}{|l|}{ Site of hospitalization } \\
\hline - $\quad$ Pediatrics wards & 6 & 12 & - \\
\hline - Intensive care unit & 9 & 18 & - \\
\hline
\end{tabular}


Table 2. Antimicrobial resistance and antimicrobials used for treatment in case and control groups treatment and antibiotic susceptibility profile

\begin{tabular}{|c|c|c|c|}
\hline Variable & $\begin{array}{l}\text { EPE } \\
(n=15)\end{array}$ & $\begin{array}{l}\begin{array}{l}\text { Non EPE } \\
(\mathbf{n}=\mathbf{3 0})\end{array} \\
\end{array}$ & OR (CI 95\%) \\
\hline \multicolumn{4}{|l|}{ Antibiotic treatment } \\
\hline - Number of antibiotics indicated ${ }^{\mathrm{a}}$ & 34 & 39 & \\
\hline - Ampicillin & 2 & 7 & $-{ }^{b}$ \\
\hline - Sulbactam-ampicillin & 0 & 3 & - \\
\hline - Cefalosphorins $2^{\text {nd }}$ gen & 2 & 8 & - \\
\hline - Cefalosphorins $3^{\text {th }}$ gen & 7 & 11 & - \\
\hline - $\quad$ Meropenem & 8 & 3 & $10.3(2.1-49.2)$ \\
\hline - Ciprofloxacin & 6 & 2 & $9.33(1.6-54.7)$ \\
\hline - Amikacin & 4 & 2 & $7(1.17-42)$ \\
\hline - Gentamicin & 2 & 6 & - \\
\hline - $\quad$ TMP-SMX & 1 & 1 & - \\
\hline Inadequate initial treatment & 11 & $2(\mathrm{n}=24)$ & $3.7(1.35-7.46)$ \\
\hline \multicolumn{4}{|l|}{ Antibiotic resistance } \\
\hline - TMP-SMX & 10 & 4 & $12(2.66-54.2)$ \\
\hline - Gentamicin & 13 & 2 & $84.5(10.6-669.6)$ \\
\hline - Amikacin & 8 & 0 & $2.1(1.25-3.68)$ \\
\hline - Ciprofloxacin & 5 & 0 & $1.5(1.05-2.15)$ \\
\hline
\end{tabular}

and one with the correct EAT. In contrast, three patients with urinary tract infections (two $K$. pneumoniae and one E. coli) responded favorably to the EAT regardless of being infected by antibioticresistant microorganisms.

The EAT was more successful for the control group $(\mathrm{P}=0.009)$; globally, antibiotic resistance was higher in EPE than in non-EPE (Table 2).

The following ESBL genes were detected by PCR:

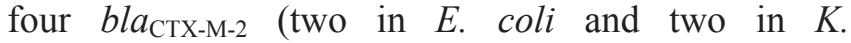
pneumoniae); four bla $a_{\mathrm{CTX}-\mathrm{M}-9}$ (two in E. cloacae and two in $K$. pneumoniae); three bla $a_{\mathrm{SHV}-5}$ (two in $S$. marcescens and one in E. coli); two bla $a_{\mathrm{CTX}-\mathrm{M}-8}$ (two $K$. pneumoniae); one bla $a_{\mathrm{CTX}-\mathrm{M}-15}$ ( in $K$. pneumoniae); and one $b a_{\mathrm{SHV}-2}$ (K. pneumoniae).

Seven of the eight amikacin-resistant isolates harbored the $a a c\left(6^{\prime}\right)-I b$ gene.

Plasmid-mediated quinolone resistance (PMQR) genes were detected in four strains, one $K$. pneumoniae strain with $q n r B$ along with $b l a_{\text {СтХ-м-8, }}$ and three bla $_{\mathrm{CTX-M-9}}$ producing strains carrying qnr $A$ (two E. cloacae and one K. pneumoniae).
Different from previous reports, we observed an increase in the relative frequency of CTX-M enzymes, other than CTX-M-2, accompanied by PMQR genes [5-7].

EPE acquisition has been linked to hospitalization, presence of severe illnesses, presence of prosthetics, and prior exposure to antibiotics, especially TGC $[2,11,12]$.

Multivariate analysis showed that previous hospitalization in the ICU was the only independent $\mathrm{RF}$ for EPE acquisition. However, to improve the detection of patients with EPE infection, the four predisposing factors detected by univariate analysis should be kept in mind. The presence of three or more of these predisposing factors (for children older than 30 days), has a sensitivity to detect patients with EPE $\sim 84.6 \%$ and a specificity $\sim 96.4 \%$. RF for $\mathrm{EPE}$ infections in newborns involves different aspects, mostly related to the perinatal period [13].

The acquisition of EPE in this study was associated with an inadequate EAT and to the usage of 
wide-spectrum antibiotics such as ciprofloxacin, amikacin and meropenem.

Concomitantly, EPE were significantly more resistant to ciprofloxacin and aminoglycosides, leading to failure of the EAT, regardless of the administration of TGC. Although quinolone usage is restricted in the pediatric population [14], five out of fifteen EPE showed co-resistance to ciprofloxacin.

\section{Conclusion}

Our work provides clinical and epidemiological information that may facilitate the characterization of EPE acquisition in the HP-CHPR. The risk factors detected in this work can be used to optimize both diagnosis and treatment of patients with probable EPE infections, regardless of hospital ward or type of infection.

\section{Acknowledgements}

We would like to express our deepest gratitude to Anaulina Silveira for her support with the statistical analyses.

This work was partially supported by grants from CSIC (Comisión Sectorial de Investigación Científica, Uruguay) to R. V.

\section{References}

1. Paschke A, Zaoutis T, Conway P, Xie D, Keren R (2010) Previous antimicrobial exposure is associated with drugresistant urinary tract infections in children. Pediatrics 125: 664-672.

2. Kim Yun-Kyung, Pai Hyunjoo, Lee Hoan-Jong, Park SE, Choi EH, Kim J, Kim JH, Kim EC (2002) Bloodstream Infections by Extended-Spectrum $\beta$-Lactamase-producing Escherichia coli and Klebsiella pneumoniae in Children: Epidemiology and Clinical Outcome. Antimicrob Agents Chemother 46: 1481-1491.

3. Bartoloni A, Pallecchi L, Riccobono E, Mantella A, Magnelli D, Di Maggio T, Villagran AL, Lara Y, Saavedra C, Strohmeyer M, Bartalasi F, Trigoso C, Rossolini GM (2013) Relentless increase of resistance to fluoroquinolones and expanded-spectrum years of surveillance in cephalosporins in Escherichia coli: 20 resource-limited settings from Latin America. Clin Microbiol Infect 19: 356-3619.

4. Tumbarello M, Spanu T, Di Bidino R, Marchetti M, Ruggeri M, Trecarichi EM, de Pascale G, Proli EM, Cauda R, Cicchetti A, Fadda G (2010) The costs of bloodstream infections caused by Escherichia coli and influence of extended-spectrum $\beta$-lactamase production and inadequate initial antibiotic therapy. Antimicrob Agents Chemother 54: 4085-4091.

5. Bado I, Cordeiro N. F, Robino L, García-Fulgueiras V, Seija V, Bazet C, Gutkind G, Ayala JA, Vignoli R (2010).
Detection of Class 1 and 2 Integrons, extended-Spectrum $\beta$ lactamases and qnr alleles in Enterobacterial isolates from the digestive tract of intensive care unit inpatients. Int $\mathrm{J}$ Antimicrob Agents 36: 453-458.

6. Garcia-Fulgueiras V, Bado I, Mota MI, Robino L, Cordeiro NF, Varela A, Algorta G, Gutkind G, Ayala JA, Vignoli R (2011) Extended-spectrum $\beta$-lactamases and plasmid-mediated quinolone resistance in enterobacterial clinical isolates in the paediatric hospital of Uruguay. J Antimicrob Chemother 66: 1725-1729.

7. Cordeiro NF, Robino L, Medina J, Seija V, Bado I, García V, Berro M, Pontet J, Lopez L, Bazet C, Rieppi G, Gutkind G, Ayala JA, Vignoli (2008) Ciprofloxacin-resistant enterobacteria harboring the aac(6')-Ib-cr variant isolated from feces of inpatients in an intensive care unit in Uruguay. Antimicrob Agents Chemother 52: 806-807.

8. Qin X, Zerr DM, Weissman SJ Englund JA, Denno DM, Klein EJ, Tarr PI, Kwong, J, Stapp JR, Tulloch LG, Galanakis, E (2008) Prevalence and Mechanisms of BroadSpectrum b-Lactam Resistance in Enterobacteriaceae: a Children's Hospital Experience. Antimicrob Agents Chemother 52: 3909-3914.

9. Clinical and Laboratory Standards Institute (2009) Performance Standards for Antimicrobial Susceptibility Testing: Nineteenth Informational Supplement M100-S19. CLSI, Wayne, PA, USA,.

10. Horan TC, Andrus M, and Dudeck MA (2008) CDC/NHSN surveillance definition of health care-associated infection and criteria for specific types of infections in the acute care setting. Am J Infect Control 36: 309-332.

11. Topaloglu R, Er I, Dogan BG, Bilginer Y, Ozaltin F, Besbas N, Ozen S, Bakkaloglu A, Gur D (2010) Risk factors in community-acquired urinary tract infections caused by ESBLproducing bacteria in children. Pediatr Nephrol 25: 919-925.

12. Vignoli R, Calvelo E, Cordeiro NF, Lucero R, Ingold E, Quintana A, Del Monte A, Schelotto F (2006) Association of broad-spectrum antibiotic use with faecal carriage of oxyiminocephalosporin-resistant enterobacteriaceae in an intensive care unit. J Hosp Infect 63: 306-315.

13. Huang Y, Zhuang S, Du M (2007) Risk factors of nosocomial infection with extended-spectrum beta-lactamase-producing bacteria in a neonatal intensive care unit in China. Infection 35: 339-345.

14. Committee on infectious diseases (2006) The use of systemic fluoroquinolones. Pediatrics 118: 1287-1292.

\section{Corresponding author}

Rafael Vignoli, MD

Alfredo Navarro 3051, 11600

Montevideo, Uruguay

Telephone/Fax: 0598-24875791

Email: rvignoli@higiene.edu.uy

Conflict of interests: No conflict of interests is declared. 